\title{
Disciplinary Culture and Effective Teaching: A Cultural Anthropological Study
}

\author{
Saeid Safaei Movahhed ${ }^{1}$ \\ ${ }^{1}$ Iranian Curriculum Studies Association(ICSA), Iran \\ Correspondence: Saeid Safaei Movahhed, Iranian Curriculum Studies Association(ICSA), Iran
}

Received: December 13, 2020

Accepted: April 12, $2021 \quad$ Online Published: April 21, 2021

doi:10.5539/hes.v11n2p179

URL: https://doi.org/10.5539/hes.v11n2p179

\begin{abstract}
During the last couple of decades, many researchers have been trying to explicate "effective teaching" in higher education. As a result, when one searches the term, a vast amount of papers and research reports pop up in the literature, involving lists of attributes and competencies of effective teachers. But the impressive point is that "effectiveness" has been viewed mostly from a technical vantage point and disciplinary differences have not received proportionate attention. At the same time, some sociologists of science began to view disciplines as tribes and territories who own their exclusive norms, rituals, and values. Hence, this research aims at investigating effective teaching in higher education within the framework of disciplinary culture. Methodologically, the research may be deemed as interpretive ethnography as it aims at representing emically how members of disciplinary cultures perceive and interpret effective teaching. Hence, based on Tony Becher classification of disciplines into civil and rural, two postgraduate classes were selected, namely from Pure Mathematics (involving 15 students to represent civil disciplines) and Education Studies (involving 18 students to represent rural disciplines). To collect data, the researcher deployed non-participant observation for a full semester and informal interviews were also conducted at regular intervals. The field notes and interview protocols were analyzed thematically to produce meaningful categories for results representation. As credibility was of great concern in the research, three strategies were used for this purpose namely member check, peer debriefing and prolonged engagement. Based on the interpretations, members of rural disciplines evaluate teaching as effective when it focuses on classic texts, cares about human and social issues, approaches laymen jargons, emphasizes understanding, appreciates variety of teaching strategies and learning styles, holds a critical stance towards cultural issues, and takes on a lenient approach in marking. On the other side, members of civil disciplines evaluate teaching as effective when it focuses on updated resources, is content-oriented, approaches professional terminology, emphasizes practicality, and takes on a tough stance on marking.
\end{abstract}

Keywords: disciplinary culture, effective teaching, higher education, educational ethnography, educational anthropology

\section{Introduction}

Whenever there is a discussion on education, schooling, further studies or any other formal learning arrangements, the typical image which comes up in one's mind is a classroom where a teacher is carrying out instructional activities before a group of students. Hence, what contributes majorly to the achievement of any educational goals is believed to be the quality of teaching (Moosapour, 2012). Although the term "teaching" is used abundantly by both the laymen and academicians, but there is little agreement over its definition, nature and functions. However, its role in learning achievement is so undeniable that many researchers and policy - makers have been trying consistently to portray how a quality teaching is conducted. These efforts are usually manifested in research reports which are entitled "effective teaching qualities" and are used both as a guideline for practice and performance appraisal. As "teaching " and "effectiveness" have pivotal roles in this study, I initially present my accepted definitions of the terms and then look critically into some related literature.

As mentioned earlier, there is no unanimous consensus over what teaching is. So, many challenging and even conflicting perspectives emerged in the literature over its nature. Some consider it as a technical function (Brundage \& Mackeracher, 1980), some as ethical (Carr, 2005), and some others as artistic (Eisner, 2002). Nesbit, Leach and Foley (2004) explored the related literature and categorized the studies on teaching into the following groups: 
- Teachers' effectiveness: Policy-makers, administrators, and parents want to know what makes teaching effective or ineffective. These studies assume that any difference in teachers skills and characteristics result in students learning achievement.

- Teaching functions: Researches on teachers' effectiveness presented an acceptable knowledge of what teachers do in practice. Teachers do not just give out information to be absorbed by students but play various roles and functions to meet effectiveness criteria.

- Teacher's beliefs and values: Assuming that teachers choose intentionally what they do, these researchers inquire into how teachers interpret, and make sense of their actions. They argue that teachers bring a set of values, a perspective, and a set of intertwined beliefs and intents to their classrooms, thorough which their practices could be justified.

- Social dynamics of classrooms and schools: it is clear that teachers do not work in a vacuum, but they carry out their roles in a social context. Hence these researchers focus on exploring the dynamics of teaching and learning as a socially contextualized practice.

- Contexts of teaching: using anthropological, autobiographical, ethnographic and sociological research methods; these researchers inquire into teaching as a cultural phenomenon. They also draw upon any analytic tools to demonstrate how local actions and procedures are impacted by global and meta-structures.

Among all the above mentioned paradigms, the cultural approach towards teaching seems to be the most all-inclusive as it gives a perspective through which teaching functions, effectiveness, values, and context can be interpreted meaningfully. This claim is to be justified further in this paper. So, I give my favorite definition of teaching here to establish it as a basis for further arguments:

"Teaching is a situated and collaborative activity which involves verbal synchronous and asynchronous communication of two or more than two people to achieve learning. Within this communicative and interactive framework, a person plays the role of a teacher(one who has valid knowledge and power of explanation and question) and one or some others play the role of students (receive knowledge; collaborate in activities; and seek , construct or critique knowledge " (Moosapour, 2012).

According to this definition teaching:

- is a situated activity and has its roots in culture.

- is a collaborative activity, so the accountability rests with both teachers and students.

- has a communicative nature, both synchronously and asynchronously.

- requires both sides to play different roles, from giving/receiving information to co-constructing knowledge.

The other term "effectiveness" is also vaguely used by both laymen and experts, so one may even witness conflicting perspectives on the term in the related literature. Fathi Vajargah \& Diba Vajari (2016) explored the various notions of educational effectiveness and categorized them into four groups:

1. effectiveness as the extent to which behavioral objectives are met.

2. effectiveness as the extent to which learning is transferred to real life situations.

3. effectiveness as conformity to standards.

4. effectiveness as customers' (learners') satisfaction

As I am focusing here on how students of different disciplines perceive effective teaching and how their perception is shaped by disciplinary culture, so the fourth definition (learners' satisfaction) is used in the current paper as the foundational definition. Hence, I am arguing here that effective teaching must be explored from a cultural contextual perspective and any effort to generate an all-inclusive list (or a meta-narrative in post modernistic terminology!) is doomed to failure.

However, effective teaching in higher education has been explored by many researchers from various fields. They have mainly tried to seek and identify effectiveness criteria and generate a list to be used as a guideline for teaching practice and teachers' appraisal. For example, Marsh (2005) believes that effective teaching in higher education consists of nine major qualities as follow:

- Possessing academic merit.

- Willingness and enthusiasm of the teacher.

- Clarity and well-organizedness.

- Group interaction.

- Personal communication. 
- Convenient content coverage.

- Fair evaluation/scoring.

- Designing and assigning convenient tasks.

- Assigning the workload with a reasonable level of difficulty.

Surveying the related literature, Chickering and Gamson (1987) identified seven major criteria for effective teaching in university as encouraging communication between teachers and students, encouraging communication among students, encouraging active learning, immediate feedback, emphasis on the time allocated to tasks, setting high expectations, respect for various learning styles and aptitudes. Fox and Hackerman(2003) are also among many others who explored what effective teaching means in higher education and came up with a five- litem list as mastering content and willingness toward it; possessing necessary skills, experience, and creativity in using various teaching strategies and technologies; mastery of different ways of making tests and using them; professional interaction with students inside and outside the classroom; and persistent effort for improving teaching and learning.

Considering that there is a vast body of literature on effective teaching in higher education, Moosapour (2012) also carried out a meta-synthesis study and generated a long list of qualities as follow: project (problem)-based learning, dialogic or dialectic learning, situational learning, inquiry-based learning, outcome-based learning, group-based learning, meaning-sensitive learning, involving personal perspectives in understanding phenomena, evaluation-based learning, networked learning, ICT-based learning, diversity learning, group-based learning, and meta-cognitive learning.

However, if one ever decides to extend the search into databases, numerous lists, works or research reports come up on the topic. But there remain unanswered questions: how disciplinary culture may influence such lists of qualities? can we inquire into qualities of effective teaching without taking into account the cultural context of a discipline? Do Mechanical Engineering undergraduates perceive effective teaching the some way the Philosophy of Science students do? Do postgraduates of Education Studies and Agricultural Engineering make sense of effective teaching the same way?

It seems that most related studies overlooked the role of disciplinary culture in how we might perceive effective teaching and took a context-free and technical stance towards the topic. This stance is in sharp contrast to how sociologists of science see the matter. They explored academic disciplines through cultural anthropological perspective in the recent decades and provided in-depth knowledge on academic tribes and territories. For example, Becher (1994) distinguished between urban and rural disciplines as follow to demonstrate better the cultural differences in academia:

- Urban disciplines: in such disciplines, people have immediate contact with authentic issues, experts focus on specific topics, scientific progress is extremely high, researchers focus on limited areas of study, team working is something typical, and work reports are short and co-authored.

- Rural disciplines: in these disciplines, people are not in close contact with real-life issues, life is not fast and exciting enough, there is little chance for group work and cooperation, and rumors go around swiftly. What is more, areas of study here are vast and their borders are porous and vaguely defined.

Bauer (1981) takes on anthropological stance as well and believes that academic disciplines should not be merely deemed as different bodies of knowledge, but they have their exclusive cultural rites, rituals and norms. For example, physicists are more reductionist than biologists, and scientists are generally more reductionist than historians, philosophers and religious scholars. On the other side, sociologists reason that knowledge is a human construct and not a reflection of outside realities, while scientists believe that valid knowledge is an objective and value-free reflection of outside world. Assuming that there is an absolute truth, natural scientists try to allocate necessary time and effort to uncover that truth, while social scientists refute any claim to an absolute truth and objective reality.

However, using a cultural perspective to look into academic disciplines may have numerous benefits. Drawing on a comparative stance, one can vividly see how disciplines differ on various aspects such as language, norms, rites and rituals. If you ever decide to join any of these tribes, you must speak their language, participate in their communities, and roughly share the same beliefs (Kirshnan, 2009). Disciplines do not have differences just on the part of context knowledge, but they differ on various, and somehow unexpected, aspects. For instance, physicists mostly have leftist political stance and always feel out of time!(Bauer, 1990).

Now justifying that each academic discipline owns their exclusive culture, the current study tries to understand how students of different disciplinary backgrounds perceive effective teaching-within their cultural tribes. This study comes out of a critical stance towards most related research reports which had a technicist and 
standardized stance towards qualities of effective teaching in higher education and failed to provide a deeper look into how culture and context may form our perception of effectiveness.

\section{Research Method}

As mentioned before, this research aims at identifying how disciplinary culture shapes students understanding of effective teaching and who an effective teacher is. Hence, when it comes to providing a cultural image, cultural anthropology and (educational) ethnography turn up as the most convenient options. Also, as there exist various definitions for culture, I initially clarify my stance towards it to provide a basis for further debate. In the current study, I draw up an interpretive definition by Andersen and Tyler (2013):

"Culture is the complex system of meaning and behavior that defines the way of life for a given group or society. It includes beliefs, values, knowledge, art, morals, laws, customs, habits, language, and dress, among other things. Culture includes way of thinking as well as patterns of behavior. Observing culture involves studying what people think, how they interact, and the objects they use".

This interpretive conception provides two benefits: first, it gives an emic perspective of how insider agents perceive a phenomenon (as I intend to understand). Secondly, it is aligned with the ethnographic design which is adopted here (interpretive ethnography). As Harris (1968) mentions:

"ethnography is a qualitative design in which the researcher describes and interprets the shared and learned patterns of values, behaviors, beliefs and language of a culture-sharing group" (cited by Cresswel,2007).

Pole and Morrison (2003) suggest the common characteristics of ethnography as follow:

- A focus on discrete location, event (s) or setting.

- A concern with the full range of social behavior within the location, event or setting.

- The use of a range of different research methods which may combine qualitative and quantitative approaches but where the emphasis is upon understanding social behavior from inside the discrete location, event or setting.

- An emphasis on data and analysis which move from detailed description to the identification of concepts and theories which are grounded in the data collected within the location, event or setting.

- An emphasis on rigorous or thorough research, where the complexities of the discrete event, location or setting are of great importance than overarching trends or generalizations.

To collect data, I deployed non-participant observation for a full semester and informal interviews were also conducted at regular intervals. The participants included 14 undergraduate and postgraduate students from the rural disciplines, namely Philosophy, Cultural Studies, History, Social Studies, and General Psychology, and 9 undergraduate and postgraduate students representing urban disciplines, namely Mechanical Engineering, Petroleum Engineering, and Civil Engineering. The participants were purposively selected by network sampling strategy. In the current paper, Becher's classification of academic disciplines into rural and urban was adopted as the main framework for observing and collecting data.

To analyze the data, a qualitative framework provided by Woods (2005) is adopted; He suggests a six-level taxonomy for analyzing qualitative data as follow:

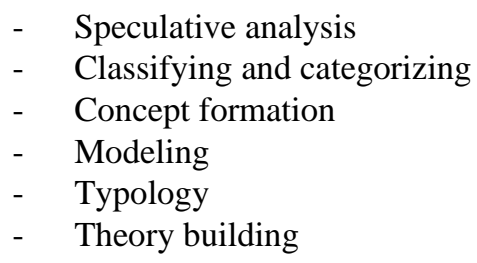

In the current study, data are analyzed up to the second level and categories are developed to represent the disciplines' cultural image. At this level, the researcher endeavors to systematically reduce and organize the mass of data from field notes, observations, interviews and documents into categories. Hence, the categories are identified and developed, sub-categories are determined, and supporting data are utilized as instance to back up them. For the purpose of credibility, member check and peer debriefing are used and finally results are displayed thematically.

\section{Results}

Based on the interpretations, effective teaching can be categorized on seven axes for dwellers of rural and urban disciplines as follow: 
- Classic vs. cutting- edge: while many researchers have reported teachers and resources' updatedness as an important indicator of effectiveness, and they are explicitly referred to in final term appraisals of teachers, but it seems that the criterion cannot be generalized to all academic disciplines. For example, students of philosophy, history, and cultural studies believe that an effective teacher must be able to introduce and teach works and books which have renowned and well-known authors. J.N, a philosophy undergraduate, says:" I expect my teacher to teach "Republic" by Plato instead of working on the most recent interpretations of the book". Also, D.Z, a history postgraduate believes: "what makes a history class appealing is working on classic works by great historians". These students usually believe that not all old works should be deemed as unworthy, and they can even indicate how rich and valuable a class is in our field. On the other side, engineering students interpret effectiveness differently and base their appraisals on updatedness. A.C, a drilling postgraduate, explains his opinion as follow: "our field undergoes rapid changes. It is really unacceptable that some of our teachers still insist on resources which go back to 17 years ago". To sum it up, it seems that disciplinary agents' interpretations are inextricably intertwined with half-life of knowledge rule. Human orientation vs. subject orientation: while teaching is a human interaction between agents (a teacher and students), but the extent to which emotional or content aspect is emphasized varies in different disciplines. Hence, dwellers of rural disciplines (e.g. Philosophy, History, Cultural Studies, etc.) consider emotional aspect as very influential in teaching and appraise their teachers' performance on how considerate they are. M.N, a psychology postgraduate, believes that "a good teacher is one who considers his students under all circumstances. Although the content is very important, but the ethical and moral aspects must be given precedence ". H.S, a Social Studies postgraduate also states that" effective teachers are mostly remembered by their conduct and respectful manners".

On the other side, what takes precedence in urban disciplines is content- orientation. Students of these disciplines perceive effective teaching as one which mostly focuses on subject rather than human concerns. For instance, a Mechanical Engineering postgraduate believes: "we are studying a hard discipline, so we expect our teachers to manage the time in a way that the desired content is covered as much as possible. Although the human aspects are vital, but they should come after context concerns". To these students, when it comes to technical decisions (especially evaluation), emotional concerns must play no role.

Multi-vocal vs. uni-vocal: seemingly, the nature of a discipline may play a vital role in what is perceived as effective or ineffective teaching. For example, as social studies are more interpretive and contextualized in nature, their agents are mostly inclined to discussion, dialogue and debate. Fazeli (2007), a renowned Iranian anthropologist, believes that Social Studies teachers must focus on expanding the critical thinking skills of students, adopt cooperative approach and give dialogue a high priority. In the current study, participants from the rural disciplines have the aforementioned perception on how teaching may turn into an effective event. A.Z, an undergraduate from Sociology, believes: "our classes are of no values if they are not based on dialogue and criticism. Sadly, just a few of our courses run like this and they remain as a fruitful memory forever". M.A, a Philosophy postgraduate, also has the same idea about effective teaching: "philosophy, as a field of study, is based on reflection and listening to the other. If a teacher desires to talk the entire class trough, we prefer not to attend the class. We are not just good listeners".

On the other part of territories, most Engineering students have rather contradictory epistemology and perceive effective teaching differently in this regard. As an instance, a postgraduate Petroleum Engineer says:" we should accept that the teacher is one who knows the subject better than us and must have control over the time. I get really furious when some wise guys interrupt the teacher to ask silly questions or comment on things they think they are aware of". It appears that dwellers of urban disciplines conceive of knowledge as an objective entity and value teaching strategies which focus more on transferring know-what and know-how.

- Layman's terms vs. professional jargons: In academic world, disciplinary terminology is expanded and developed to defend a discipline's identity and body of knowledge against any external aggression. If disciplinary language can be easily understood by the grassroots, its experts may lose their position as the main interpreters of accumulated body of knowledge. Possibly, it can be claimed that disciplinary scholars intentionally use complicated terms or jargons to raise their routine observations to academic levels (Krishnan, 2009).

Although disciplinary language plays a prominent part in maintaining a discipline's position in academia, but the participants from rural disciplines do not deem it as a contributing factor to effective teaching. F.S, a Social Studies postgraduate, voices her concern as follow:" some teachers use complicated language or jargons to act like a knowledgeable expert. I am wondering why these guys don't try to represent real social concerns and maladies explicitly and with a simple language." A.T, a postgraduate student of Philosophy, 
thinks roughly alike:" our classes have turned into bunch of complicated and confusing speeches which are hard to understand. The more we hear, the less we get."

On the other side of academic territories; jargons and symbols are seen differently. Agents of urban disciplines are mostly meticulous about using professional terminology and defend their academic borders more rigorously. For example, A.SH, a Civil Engineer undergraduate states: "we usually appraise our teachers by the extent to which they use our professional terminology. Any way, you can't claim to be a professional teacher and speak like a layman! Professional concepts and terms logically can't be used interchangeably. Laymen don't understand us because they aren't professionals."

- Critical vs. practical: within a disciplinary culture, learners' perception of effective teaching is bound up with how much they benefit from teaching. In the current study participants from the rural disciplines deem effective teaching as one that offers a critical and deeper understanding of the world around. P.R, a postgraduate student from psychology, believes:" teaching should not be very abstract and covers mere facts. A good teaching should render us a critical understanding about human and social problems." S.M, another postgraduate from Cultural Studies, suggests:" Some teachers raise us so high to skies that we have no sense on what is going on the ground. We hate this; we must lastly be able to understand better our society."

On the other part, Engineering students see practicality as a major contributing factor to effective teaching and place more emphasis on real problem-solving. A.S, Civil Engineer undergraduate protests explicitly against her current classes:" some teachers seemingly don't understand that we are not going to graduate as pure mathematician or physicist. We will probably be employed to solve real problems and give practical solution. Will we really need such a large number of abstract formulas? M.G, a Petroleum Engineer, looks critical and aggressive as well: "I'm studying this field for years, but I have never seen an oil well from a close distance. We have just had some experiments in the laboratory. Of course, some teachers drew the well on the blackboard by a piece of chalk, teachers here just talk aloud and know- how is not offered to us."

\section{Discussion}

Based on the above-mentioned findings, effective teaching in rural and urban disciplines may be summarized in the following table:

Table 1. Rural and Urban Disciplines in Contrast

\begin{tabular}{|c|c|c|}
\hline Criteria & Rural Disciplines & Urban Disciplines \\
\hline Resources & clas & cut \\
\hline Emphasis & human orientation & content orientation \\
\hline Language & layman language & professional terminology \\
\hline Benefits & critical understanding & practical know-how \\
\hline
\end{tabular}

As mentioned in the introduction, many studies that looked into effective teaching in higher education just ended up in long and seemingly all-inclusive lists and paid little attention to disciplinary differences (e.g. Al-hinai, Aschenbrener, Terry, Torres, 2010; Chism, 20011, Delvin and Samarawickrema, 2010). This is while many sociologists of science studied cultural differences of disciplines passionately and published renowned and influential works (e.g., Becher, 1994; Bauer, 1990; Neisi and Gardner, 2006; Belamy, 2010). Hence, the current study takes an anthropological stance to study effective teaching within a disciplinary culture framework in social studies and engineering fields.

As expected, dwellers of various academic territories conceive of effective teaching differently. Therefore, it is expected that these cultural differences be taken into account in making decisions such as teachers' recruitment, appraisal and development.

This research focused on how postgraduate students view effective teaching in their disciplinary culture. To illuminate a better image of disciplinary culture, we need to involve other members of the cultures such as undergraduate students and instructors as well.

The findings may help universities' officials to devise proportionate and amenable criteria for recruitment and appraisal of instructors, based on disciplinary differences, and refrain from imposing global standards and meta-narratives on various fields of study.

People usually hold a unit standard in their mind when they talk about effective instructors. They may become aware how teaching functions are influenced by disciplinary culture and take into account the differences in their judgments. 


\section{References}

All-Hinai, N. S. (2011). Effective college teaching and students' ratings of teachers: what students think, what faculty believes, and HAT actual ratings show implications for policy and practice in teaching quality assurance and control in higher education in Oman. Durham theses, Durham University.

Andersen, M. L., \& Taylor, H. F. (2013). Sociology: the essentials. Wadsworth, Gengage Learning, Belmont.

Aschenbrener, M. S., Terry, Jr., R., \& Torres, R. M. (2010). Creative and effective teaching behaviors of university instructors as perceived by students. Journal of Agricultural Education, 51(3), 64-75. https://doi.org/10.5032/jae.2010.03064

Bauer, H. (1990). A dialectical discussion on the nature of disciplines and disciplinarity. Social Epistemology, $4(2), 215-227$.

Becher, T. (1994). The significance of disciplinary differences. Studies in Higher Education, 1962, $151-161$. https://doi.org/10.1080/03075079412331382007

Bellamy, S. (2010). Towards a cultural understanding of academic worlds. International Review of business research papers, 6(5), 46-57.

Bergquisot, W. H. (1992). The four cultures of the academy: insights and strategies for improving leadership in collegiate organizations. Jossey- Bass Inc., publishers.

Chickering, A. W., \& Gamson, Z. F. (1987). Seven principles for good practice in undergraduate education. The Wingspread Journal, 9(2).

Chism, N. V. N. (2004). Characteristics of effective teaching in higher education: between definitional despair and certainty. Journal on Excellence in College Teaching, 15(3), 5-36.

Creswell, J. W. (2007). Qualitative inquiry and research design. Sage Publications, Inc. London.

Delvin, M., \& Samarawickrema, G. (2010). The criteria of effective teaching in a changing higher education context. Higher Education Research and Development, 29(2), 111-124. https://doi.org/10.1080/07294360903244398

Duarte, F. P. (2013). Conceptions of good teaching by good teachers: case studies from and Australian University Journal of University Teaching and Learning Practice, 10(1), 1-15.

Fathi, V. K., \& Diba, V. T. (2016). Evaluating the effectiveness of training programs. Ayij Publications, Tehran [Persian].

Krishnan, A. (2009). What are academic disciplines. ESRC National Centre for Research Methods.

Moran, J. (2002). Interdisciplinary. Rutledge, New York.

Mousapour, N. (2013). Univesity teaching: what method? What model? Researches on Education and Learning, $3(2), 49-78$.

Pole, C., \& Morrison, M. (2003). Ethnography for Education. Glasgow, Open University Press.

Safaei, M. S., \& Mohebbat, H. (2012). Sociology of Education. Ayij Publications, Tehran.

Tischler, H. L. (2011). Introduction to Sociology. Gengage Learning, WADSWORTH.

Woods, P. (1986). Inside schools: ethnography in educational research. Routledge Farmers, London.

\section{Copyrights}

Copyright for this article is retained by the author(s), with first publication rights granted to the journal.

This is an open-access article distributed under the terms and conditions of the Creative Commons Attribution license (http://creativecommons.org/licenses/by/4.0/). 